\title{
A Study of a Venture Company's Control Rights Allocation Model
}

\author{
Hiromi Sakakibara ${ }^{1}$, Shuichi Ishida ${ }^{1}$, Takashi Natori ${ }^{1} \&$ Nobuaki Minato ${ }^{1}$ \\ ${ }^{1}$ Ritsumeikan University, Osaka, Japan \\ Correspondence: Hiromi Sakakibara, 2-150 Iwakura-Cho, Ibaraki, OSAKA 567-8570 Japan. Tel: \\ 81-7036697545 (office), E-mail: hiro.skb@spa.nifty.com \\ Received: November 11, 2017 \\ Accepted: November 27, 2017 \\ Online Published: December 27, 2017 \\ doi:10.5539/ass.v14n1p160 \\ URL: https://doi.org/10.5539/ass.v14n1p160
}

\begin{abstract}
This paper proposes an allocation model of control rights between entrepreneurs and investors to properly manage venture companies. The basic concept of this model involves reflecting the company's future market value in its control rights to entrepreneurs as an incentive, while securing investors' minimum monetary requirements. Previous studies reveal that entrepreneurs' control rights gradually dilute as the monetary requirement increases in multi-staged financing; therefore, it is necessary to establish a fundamental rule for control rights allocations in initial contracts. This model also has the capability to allocate cash flow rights, and the potential capability to justify its premium.
\end{abstract}

Keywords: Venture company, control rights, allocation model, entrepreneur, investor, multi-stage financing

\section{Introduction}

One key element for a venture corporation's success includes the appropriate involvement of both entrepreneurs and investors in management. Entrepreneurs must develop and operate the business, as well as report its progress to investors; such investors as venture capitalists may monitor, supervise and instruct the company based on their knowledge. Each should understand their roles, and will be expected to become appropriately involved in the company's management. The optimisation of governance, such as control rights, is necessary to facilitate the appropriate involvement of entrepreneurs and investors. However, as negotiations are made between entrepreneurs and investors at every milestone in staged financing, cash-rich investors receive more negotiation power than cash-constrained entrepreneurs in later rounds due to the larger monetary requirements.

This paper proposes an allocation model for control rights by using the company's future target value, both anticipated and agreed upon by entrepreneurs and investors (the target value). This is intended to mitigate the unfairness of the negotiation power caused by monetary capability. Further discussed is the necessity to determine the allocation rule at the project's initial stage, consisting of multi-staged financing. Based on this model, entrepreneurs may have more control rights by enlarging the company's future value as a result of a better development status. The concept of allocating control rights by target value is especially attractive for cash-constrained entrepreneurs; the model can consequently provide new entrepreneurs with incentives to encourage innovation. Alternatively, investors can become more involved in management if the development status worsens; in other words, they can secure or even protect their profitability by introducing a model dependent upon the progress of development. Additionally, increased independent cooperation between entrepreneurs and investors is anticipated in attaining the company's clear, agreed-upon target value.

This paper defines control rights and/or management rights as the directors' voting rights in the board meeting, which represents the shareholders, except in the prior study referenced in Chapter 2.

\section{Previous Studies}

\subsection{Management's rights in staged financing}

Venture companies typically use staged financing with multiple rounds in the company's development, as Figure 1 illustrates.

A comprehensive study was made by Kaplan and Stronberg (2003) on the components of contracts between entrepreneurs and investors involved 213 financial rounds, with 119 venture companies supported by 14 investors. The authors' study reveals that re-negotiation is made in staged financing between the entrepreneurs and investors in a new financing round from previous contracts, and the entrepreneurs' voting rights decrease in 
later rounds due to an increase in monetary requirements. This result is consistent with the research by Hellmann (1998), in that cash-constrained entrepreneurs may tend to release the company's management rights, as Table 1 illustrates.

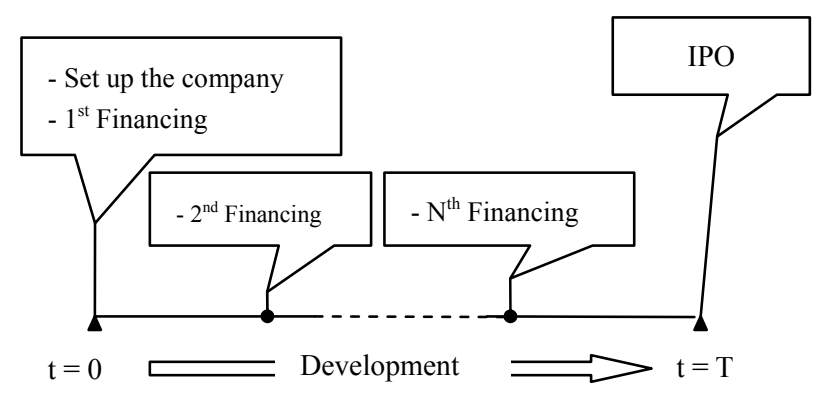

Figure 1. Staged Financing

Table 1. Allocation of voting rights (Kapan \& Stromberg, 2003)

\begin{tabular}{ccc}
\hline Holder & Initial Financing Round & All Financing Rounds \\
\hline Entrepreneurs & $29.8 \%-42.9 \%$ & $24.5 \%-33.7 \%$ \\
Investors & $46.3 \%-58.9 \%$ & $53.6 \%-62.3 \%$ \\
Others & $10.9 \%-11.3 \%$ & $12.6 \%-13.1 \%$ \\
\hline
\end{tabular}

\subsection{Management rights and financing rounds}

Aghion and Bolton (1992) incorporated the incomplete contract approach in a study of the optimisation of management rights, with the assumption that overall, information cannot be observed at the timing of initial contracts. This concept is demonstrated in Figure 2.

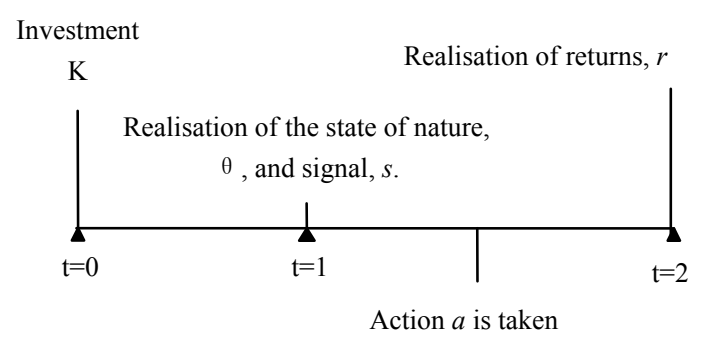

Figure 2. Incomplete Contract Approach (Aghion \& Bolton, 1992)

This concept notes that an imbalance of information always exists between entrepreneurs' $(=\theta)$ and investors' information. Further, entrepreneurs' interests are not always the same as the company's. An analysis regarding the optimisation of action, which the company takes if management rights belong to entrepreneurs or investors, reveals that entrepreneurs typically have more management rights. However, these rights are shifted to investors if the entrepreneurs cannot satisfy the investors' requirements. From a financing perspective, these shifts are consistent with entrepreneurs' behaviour, in that the entrepreneurs attempt to provide funds by the dead deals without voting rights, and attempt to fund through equity with voting rights if the finance is insufficient for development. Remarks are made to retain control rights, and entrepreneurs are to fulfil their payment duties towards this debt.

\subsection{Control and cash flow rights}

Li and Zhou (2012) established the financing contract model to provide a theoretical explanation for Kapan and Stromberg's empirical research regarding the disproportionality between cash flow and control rights. They conclude that the entrepreneurs' and investors' judgment of a firm's probability of success will affect the allocation of both control and cash flow rights. Moreover, the higher the investor assesses the entrepreneur's creativity and ability, then the less cash flow and control rights the investor requires. The paper also notes that the investor gains are complementary in the cash flow and control rights at the venture company's onset. In other words, the more cash flow rights the investor requires, the less control rights they will gain. Finally, the paper concluded with a renegotiation regarding the allocation of cash flow and control rights in multi-staged financing. 
Based on this new information, it can be posited that venture companies' dynamic allocation of cash flow and control rights requires more detailed research.

Sakakibara, Ishida, Genba, and Tao (2012) propose the concept that control rights between entrepreneurs and investors should be allocated by future company value independently of the financial structure of the company in order to protect and encourage cash-constrained entrepreneurs.

Van der Burg and Prints (2010) discuss a new system of firm governance of which the voting rights is to be delegated to proxy voting institutions.

Galai and Wiener (2008) proposed a model that allocates voting rights in board meetings by stakeholders' incremental value, at an exchange of one dollar per stake. This study also explained the merit in saving internal costs to monitor the company's operations status. This concept can be applied to companies in which voting rights can be allocated, regardless of the financing structure, such as LLCs and LLPs.

He and Sommer (2010) investigate the separation of ownership and control for board composition with the hypothesis that agency costs associated with manager-owner conflicts increase with the degree of separation of ownership and control.

\subsection{Finance method}

Marx (1998) notes that the best financing methodology between cash-constrained entrepreneurs and investors involves a combination of debt and capital, as this structure provides investors with the opportunity to manage the company, while providing entrepreneurs with an incentive.

Gebhard and Schhmidt (2006) show a combination of convertible securities and contingent control rights can be used to resolve the conflict of interests between entrepreneurs and investors.

\subsection{Research question}

Previous studies reveal the qualifying characteristics of contracts between entrepreneurs and investors, which differ in their timing due to the entrepreneurs' monetary restrictions. Regarding multi-stage financing, entrepreneurs especially have stronger negotiation power in the initial round than in subsequent rounds. Therefore, if a clear contract rule on control rights allocations is established in the initial round, entrepreneurs do not experience the problems imposed by investors in a later round. Therefore, the research questions are as follows:

- Does an allocation model of control rights correctly represent previous studies?

- Is the model trustworthy and acceptable to both entrepreneurs and investors in its theoretical aspect?

This paper posits that a venture company's value is considered and measured by an expected value at a certain time in the future - for example, an initial public offering price - and proposes a control rights allocation model based on the expected (target) value. Thus, a zero coupon bond model is applied to calculate the allocation of control rights. The fundamental behaviour is numerically studied with the model's application to multi-staged financing by analysing scenario studies.

\section{Methodology}

\subsection{The company's structure}

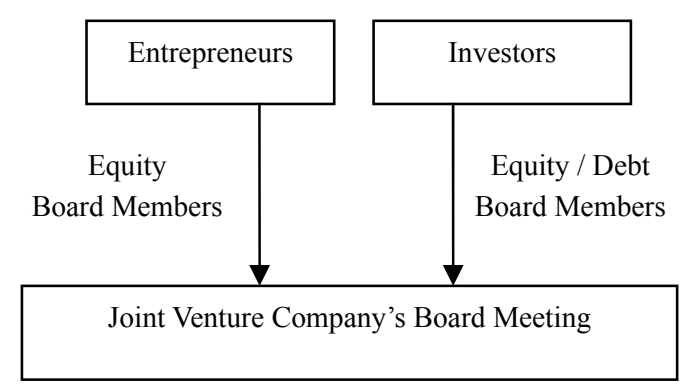

Figure 3. Joint Venture Company’s Structure

This paper studies the allocation of voting rights as control rights in a joint venture company, in which an entrepreneur and an investor choose to invest. Figure 3 illustrates the structure; while typically voting rights are allocated based on the share of equity, this study uses the company's target value regardless of actual equity and/or debt investment. 
This study assumes a development project in which the target value is VT in T years, with the estimated development cost for $\mathrm{T}$ year period as $\mathrm{V} 0$, the relationship among VT is $\mathrm{V} 0$, and the overall project profitability $\mathrm{r}$ $(\%)$ is simply calculated as the following equation:

$$
\mathrm{V} 0=\mathrm{VT} \exp (-\mathrm{rT})
$$

An entrepreneur and investor then agree on the project's profitability and commit to investing the necessary funds in the project at the present value of S0 and B0:

$$
\mathrm{V} 0=\mathrm{S} 0+\mathrm{B} 0
$$

Voting rights in common business practice are simply calculated as

$$
\begin{aligned}
& \mathrm{VRe}=\mathrm{S} 0 / \mathrm{V} 0 \text { (entrepreneur) } \\
& \mathrm{VRi}=\mathrm{B} 0 / \mathrm{V} 0 \text { (investor) }
\end{aligned}
$$

In this paper, $\mathrm{S} 0$ and $\mathrm{B} 0$ are calculated from the target value VT, which is expected and agreed upon as the target price at a certain future time, such as the initial public offering (IPO). This paper calculates S0 and V0 by assuming the investor's investment has a similar characteristic as the zero coupon bond or the convertible debt of the face value F, with maturity at the IPO (the zero coupon bond model). Figure 4 indicates the relationship between VT, F, V0, B0 and S0 based on this assumption.

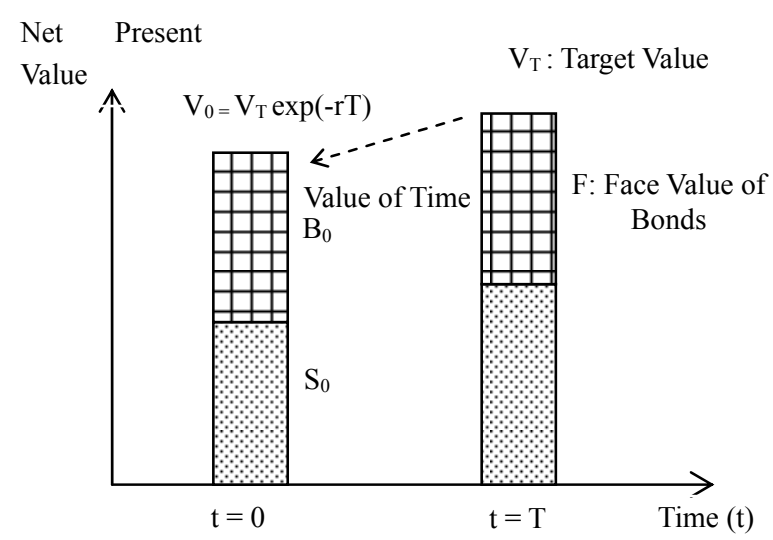

Figure 4. Relationship between $\mathrm{V}_{\mathrm{T}}, \mathrm{F}, \mathrm{V}_{0}, \mathrm{~B}_{0}$ and $\mathrm{S}_{0}$

As V0 indicates the necessary development costs, $\mathrm{B} 0$ can be the net present value of the investor's commitment to invest in the company, and S0 is the net present value of the entrepreneur's commitment. This absorbs the difference between $\mathrm{V} 0$ and $\mathrm{B} 0$. The entrepreneur, in other words, is responsible for the variance in future target value, and bears both the incentive and the penalty.

Applying the zero coupon bond model proposed by Merton, R. (1973) allows VT, F, V0, B0 and S0 to be calculated by Equations (5) and (6):

$$
\begin{gathered}
\mathrm{S}_{0}=\mathrm{V}_{\mathrm{T}} \mathrm{e}^{-\mathrm{rT}} \Phi\left(\mathrm{d}_{1}^{\prime}\right)-\mathrm{Fe}^{-\mathrm{rT}} \Phi\left(\mathrm{d}_{2}^{\prime}\right) \\
\mathrm{B}_{0}=\mathrm{V}_{\mathrm{T}} \mathrm{e}^{-\mathrm{rT}} \Phi\left(-\mathrm{d}_{1}^{\prime}\right)+\mathrm{Fe}^{-\mathrm{rT}} \Phi\left(\mathrm{d}_{2}^{\prime}\right) \\
\mathrm{d}_{1}^{\prime}=\left[\ln \left(\mathrm{V}_{\mathrm{T}} / \mathrm{F}\right)+\left(\frac{1}{2} \sigma^{2}\right) \mathrm{T}\right] / \sigma \sqrt{\mathrm{T}} \\
\mathrm{d}_{2}^{\prime}=\left[\ln \left(\mathrm{V}_{\mathrm{T}} / \mathrm{F}\right)-\left(\frac{1}{2} \sigma^{2}\right) \mathrm{T}\right] / \sigma \sqrt{\mathrm{T}} \\
\Phi=\text { Normal Distribution CDF } \\
\sigma=\text { Volatility (Uncertainty) }
\end{gathered}
$$

The profitability of entrepreneur re and investor ri can then be calculated by the following equations:

$$
\begin{aligned}
\mathrm{re} & =\ln (\mathrm{S} 0 /(\mathrm{VT}-\mathrm{F})) / \mathrm{T} \\
\mathrm{ri} & =\ln (\mathrm{B} 0 / \mathrm{F}) / \mathrm{T}
\end{aligned}
$$




\subsection{Fundamental characteristics}

Figure 5 displays the model's fundamental characteristic. Under certain conditions, the target value VT and the voting rights of the entrepreneur VRe and investors VRi are calculated. As the VT increases, VRe increases, while VRi decreases. Thus, the investor has more voting rights as an incentive when development progresses well. In contrast, as the target value VT decreases, the entrepreneur's voting rights decrease VRe, while the investor's voting rights VRi increase. Thus, the investors can be involved in the company's operations, which indicates more strongly to the entrepreneur when the development does not progress well or as anticipated.

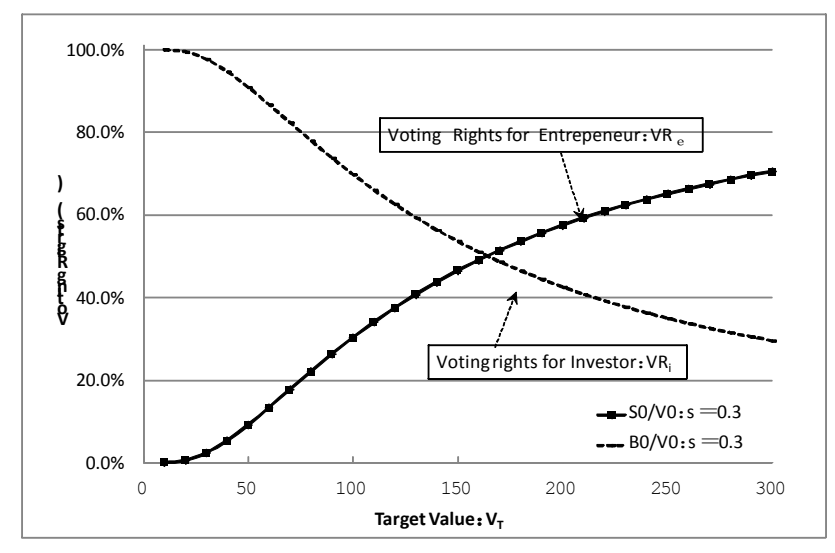

( $\mathrm{F}=\mathrm{US} \$ 90$ million, $\mathrm{r}=10 \%, \sigma=0.3, \mathrm{~T}=5$ years)

Figure 5. The Target Value and Voting Rights

\subsection{Uncertainty and cash flow rights}

Table 2 illustrates the impact of uncertainty on voting rights. When the uncertainty $\sigma$ increases, the voting rights of entrepreneurs VRe increase, while the voting rights of investors VRi decrease. This result represents the previous study, in that the investor requests higher profitability in the case of much uncertainty. The model allocates higher profitability to the investor in the case of higher uncertainty, while it provides more control right to the entrepreneur to handle such uncertainty. However, it seems reasonable that the entrepreneur assumes all monetary merit and risk from this uncertainty.

Regarding profitability, as uncertainty $\sigma$ increases, the investor's profitability ri increases, while the entrepreneur's profitability re decreases. This is a type of trade-off between control rights and cash flow rights from a risk-hedging perspective. This model represents the previous study, in that the control rights and cash flow rights are complementary.

Table 2. Impact of uncertainty

\begin{tabular}{|c|c|c|c|c|c|c|c|}
\hline $\begin{array}{c}\text { Uncertainty } \\
\sigma\end{array}$ & V0 & S0 & B0 & VRe & VRi & \multicolumn{2}{|c|}{ Profitability } \\
\cline { 6 - 9 } & & & & & & re & ri \\
\hline 0.00 & 91.0 & 36.4 & 54.6 & $40.0 \%$ & $60.0 \%$ & $10.0 \%$ & $10.0 \%$ \\
\hline 0.10 & 91.0 & 36.5 & 54.5 & $40.1 \%$ & $59.9 \%$ & $10.0 \%$ & $10.0 \%$ \\
\hline 0.20 & 91.0 & 38.3 & 52.6 & $42.1 \%$ & $57.9 \%$ & $9.0 \%$ & $10.7 \%$ \\
\hline 0.30 & 91.0 & 42.3 & 48.7 & $46.5 \%$ & $53.5 \%$ & $7.0 \%$ & $12.3 \%$ \\
\hline 0.40 & 91.0 & 47.0 & 44.0 & $51.6 \%$ & $48.4 \%$ & $4.9 \%$ & $14.3 \%$ \\
\hline
\end{tabular}

\subsection{Expansion to the premium calculation}

The model has the potential capability to justify or calculate the premium as a function of uncertainty. Premium $\mathrm{P}$ is the initial payment, separately paid to the entrepreneur when the investor decides to invest in the venture company. This amount is decided through negotiations between the entrepreneur and the investor, and no clear guideline exists to calculate. The actual exposure of the entrepreneur Sreal and the investor Breal can be calculated as a function of uncertainty:

$$
\text { Sreal }=\mathrm{S} 0(\sigma)-\mathrm{P}
$$




$$
\text { Breal }=\mathrm{B} 0(\sigma)+\mathrm{P}
$$

Then, P can be calculated:

$$
\mathrm{P}=\mathrm{P}(\sigma)=\text { Breal }-\mathrm{B} 0(\sigma)=\mathrm{S} 0(\sigma) \text { - Sreal }
$$

The above equation indicates that $\mathrm{P}$ is also the function of uncertainty $\sigma$. This is a critical characteristic to justify the relationship between the premium and uncertainty. For example, if the entrepreneur and the investor agreed that their profitability should be the same under risk-free conditions, then Sreal and Breal can be considered as $\mathrm{S} 0(\sigma=0)$ and $\mathrm{B} 0(\sigma=0)$, as in Table 2. Therefore, premium P can be calculated as a function of uncertainty $\sigma$ through the following equation:

$$
\mathrm{P}=\mathrm{P}(\sigma)=\mathrm{B} 0(\sigma=0)-\mathrm{B} 0(\sigma)=\mathrm{S} 0(\sigma)-\mathrm{S} 0(\sigma=0)
$$

\subsection{Validating the model}

When entrepreneurs decide to invite investors to a venture company, investors will request appropriate returns on their investment to satisfy their internal criteria. Entrepreneurs may alternatively request a premium for their invitation, although investors consider this premium as a part of their investment.

An initial negotiation is typically made between entrepreneurs and investors by considering the venture company's expected value through an independent valuation and estimation. If the company's estimated value differs between entrepreneurs and investors and substantially deviates from an acceptable level, an initial contract cannot be concluded. In other words, when the initial contract concludes, a significant gap does not exist in the company's expected values as calculated by both entrepreneurs and investors. Therefore, it can be observed that the model explains this implied initial agreement, and its application in the actual contract is realistic.

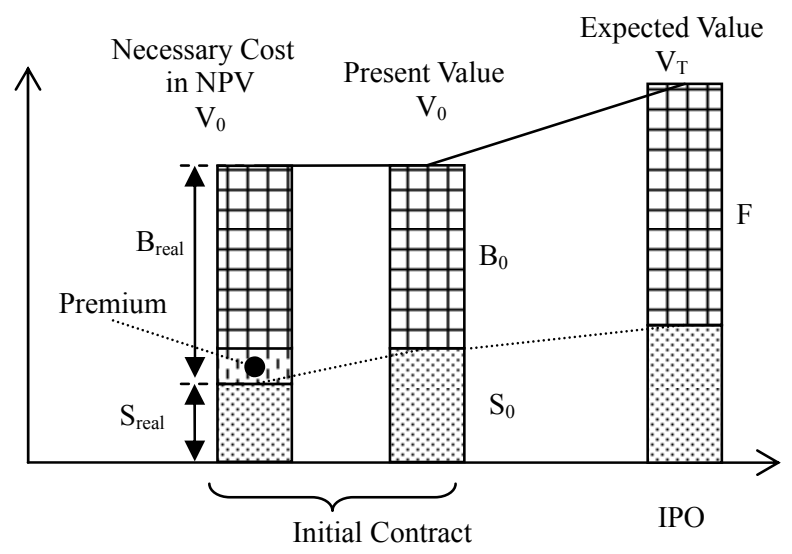

Figure 6. Shared Allocation at the Initial Contract

\section{Application to Multi-Stage Financing}

\subsection{Period remaining in the target year}

Figure 7 provides a numerical example of the model demonstrating the relationship between the remaining period $t$ and voting rights. The entrepreneur's voting rights VRe are greater at the early stage to allow the entrepreneur to more easily control the company; as the period becomes closer to the target year, voting rights decrease to approximately $40 \%$. Alternatively, investors' voting rights VRi increase as the period is close to the target year to allow investors to become involved in the company's operations and more easily request repayment. As VT is set at $\$ 150$ million and $\mathrm{F}$ equals $\$ 90$ million, the following equation can calculate the monetary contribution at the target year:

$$
\begin{aligned}
& (\mathrm{VT}-\mathrm{F}) / \mathrm{VT}=40 \% \text { (entrepreneur) } \\
& \mathrm{F} / \mathrm{VT}=60 \% \text { (investor) }
\end{aligned}
$$

Therefore, the model correctly reflects the entrepreneur's and investor's monetary contributions at the target year. This trend is enhanced if the volatility is greater. 


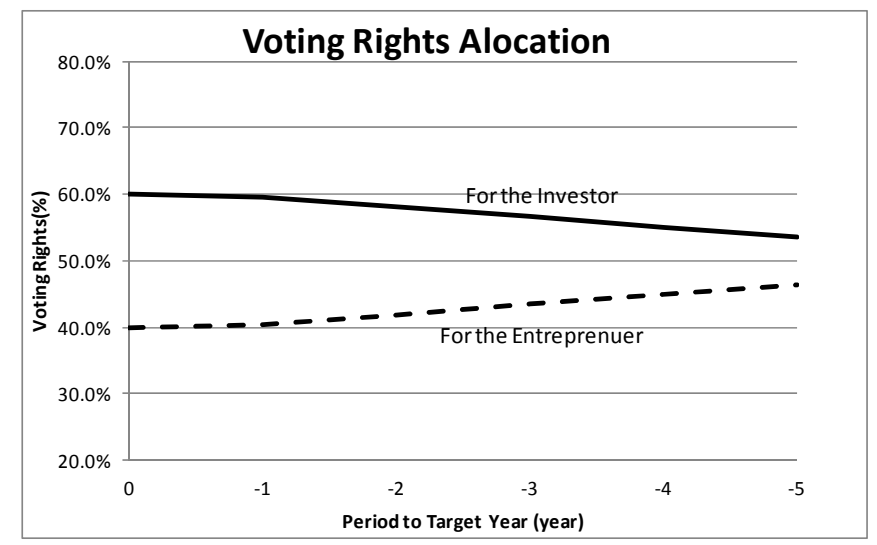

$(\mathrm{VT}=\$ 150$ million, $\mathrm{F}=\$ 90$ million, $\mathrm{r}=10 \%, \sigma=0.3)$

Figure 7. Voting Rights_-Period Remaining to Target Year

\subsection{Change in target value}

Figure 8 illustrates the change in voting rights allocations between the entrepreneur and investor in the scenario in which the target value changes. These scenarios include:

- 'Value up' scenario (+10\%): A VT increase in the -2 year, from $\$ 150$ to $\$ 165$ million

- 'Value down' scenario (-10\%): A VT decrease in the -2 year, from $\$ 150$ to $\$ 135$ million

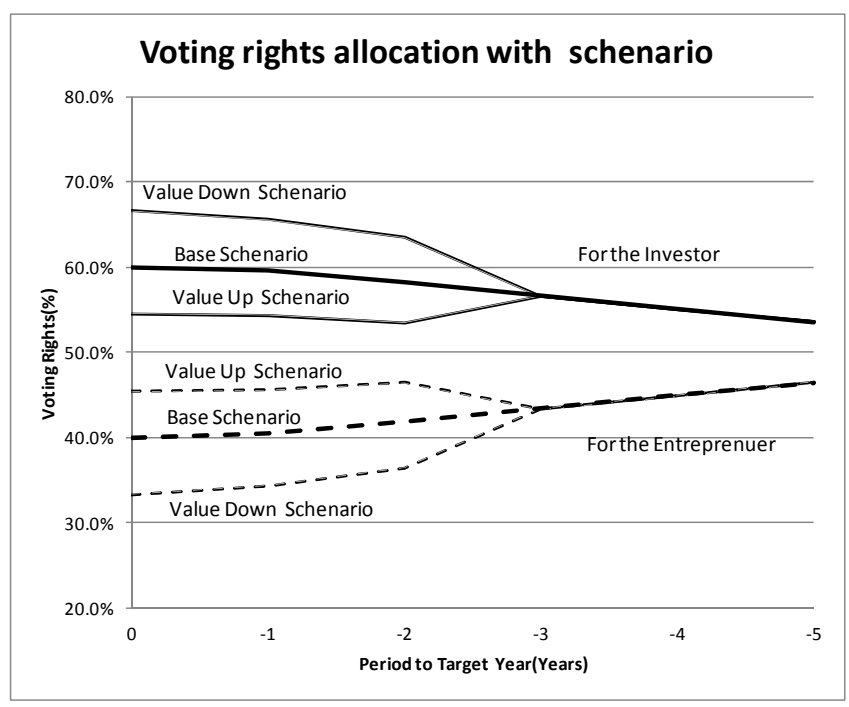

$(\mathrm{VT}=\$ 150$ million, $\mathrm{F}=\$ 90$ million, $\mathrm{r}=10 \%, \sigma=0.3)$

Figure 8. Study of Changes in Target Value Scenarios

Renegotiation in multi-stage financing will be made at every financial stage using the new obtained information. In this case, the entrepreneur's voting rights VRe increase as an incentive as the VT increases, while the investor's voting rights VRi decreases. In contrast, the entrepreneur's voting rights VRe decrease as the VT decreases, while the investor's voting rights VRi increase to strengthen indicating and monitoring rights.

\subsection{Further downside scenario}

Figure 9 illustrates the change in voting rights allocations between the entrepreneur and the investor with a 'cost up' scenario, as well as an extension of the development period as a 'down side' scenario. This scenario is described as follows:

- Three years after the investment decision (two years from the original target year and four years to the new target year), it was discovered that development costs would increase.

- Investors would compensate for this by investing additional funds, equal to $20 \%$ of the original $\mathrm{F}$ (or $\$ 90$ to $\$ 108$ million).

- The development period would be anticipated to extend by two years.

- $\quad$ The VT does not change, at VT $=\$ 150$ million. 


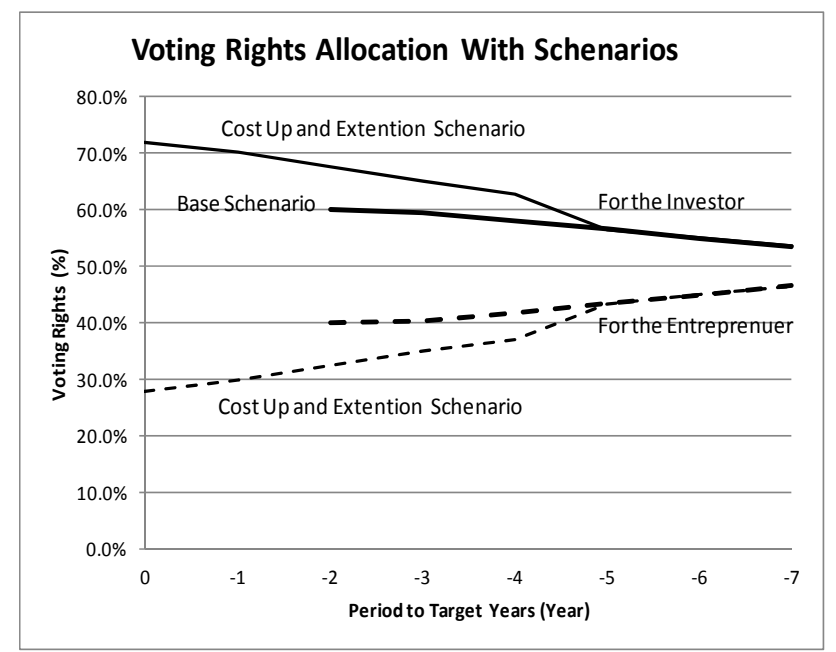

$(\mathrm{VT}=\$ 150$ million, $\mathrm{F}=\$ 90$ million, $\mathrm{r}=10 \%, \sigma=0.3)$

Figure 9. 'Down Side' Scenario-Increased Development Costs with a Period Extension

Figure 9 indicates that if the development status information is found to have worsened, then voting rights are significantly affected. Further, a cash-constrained entrepreneur typically cannot absorbed incremental development costs, and investors might invest additional funds under severe monitoring. As a result of this new investment, the investor's voting rights investor VRi would increase to allow for the investor to have severe monitoring rights.

\section{Conclusion}

This study proposes an allocation model for the control rights between the entrepreneur and the investor. This model is based on the zero coupon bond model, and interprets the behaviour of entrepreneurs and investors that previous studies have revealed and explained. In other words, this model essentially illustrates the contract between entrepreneurs and investors.

Considering entrepreneurs' weaker negotiation power due to cash limitations, the model's application as a negotiation rule in multi-stage financing can protect entrepreneurs by providing a level playing field to negotiate with investors. Moreover, the allocation of greater control rights to entrepreneurs when the situation progresses well, and to investors when it does not, is essentially acceptable for both entrepreneurs and investors. The model has the capability not only to allocate cash flow rights as a complementary set of control rights, but also the potential to quantify and justify the premiums paid by the investor to the entrepreneur. Further study is anticipated in this area.

Finally, this model is the first to distribute control rights by the progress of development. Stock options from the initial public offering are used as a tool to motivate entrepreneurs; however, the model provides a new idea of incentives to allocate greater control rights to entrepreneurs based on target values in the future.

\section{References}

Aghion, P., \& Bolton, P. (1992). An incomplete contracts approach to financial contracting. The Review of Economic Studies, 59(3), 473-494. https://doi.org/10.2307/2297860

Galai, D., \& Wiener, Z. (2008). Stakeholders and the composition of the voting rights of the board of directors. Journal of Corporate Finance, 14(2), 107-117. https://doi.org/10.2139/ssrn.1087905

Gebhard, G., \& Schhmidt, K. M. (2006). Conditional allocation of control rights in venture capital finance. Retrieved from https://papers.ssrn.com/sol3/papers.cfm?abstract_id=911527

He, E. \& Sommer, D.W. (2010), Separation of ownership and control: Implications for board composition. Journal of Risk and Insurance, 77(2), 265-295. https://doi.org/10.1111/j.1539-6975.2010.01351.x

Hellmann, H. T. (1998). The allocation of control rights in venture capital contracts. The Rand Journal of Economics, 29(1), 57-76. https://doi.org/10.2307/2555816

Kaplan, S. N., \& Stromberg, P. (2003). Financial contracting theory meets the real world: An empirical analysis of venture capital contracts. The Review of Economic Studies, 70(2), 281-315. https://doi.org/10.1111/1467-937x.00245 
Li, Y., \& Zhou, Z. (2012). Research on the allocation of cash flow rights and control rights in venture capital financing contract. Modern Economy, 3(1), 54-60. https://doi.org/10.4236/me.2012.31008

Marx, L.M. (1998). Efficient venture capital financing combining debt and equity. Review of Economic Design, 3(4), 371-387. https://doi.org/10.1007/s100580050022

Merton, R. (1973). On the pricing of corporate debt: The risk structure of interest rates. The Journal of Finance, 29(2), 449-470. https://doi.org/10.1111/j.1540-6261.1974.tb03058.x

Sakakibara, H., Ishida, S., Genba, K., \& Tao, K. (2012). Study on the allocation model of control rights for an R\&D-oriented venture company based on the future company value and its application to staging capital with financing rounds (in Japanese). Journal of the Japan Association for Management Systems, 29(2), 113-121.

Van der Burg, T., \& Prints, A. (2010). Empowering firm owners by separating voting from buying and selling shares. Review of Social Economy, 68(1), 69-91. https://doi.org/10.1080/00346760902908708

\section{Copyrights}

Copyright for this article is retained by the author(s), with first publication rights granted to the journal.

This is an open-access article distributed under the terms and conditions of the Creative Commons Attribution license (http://creativecommons.org/licenses/by/4.0/). 